\title{
SUNNIS AND SHI'A
}




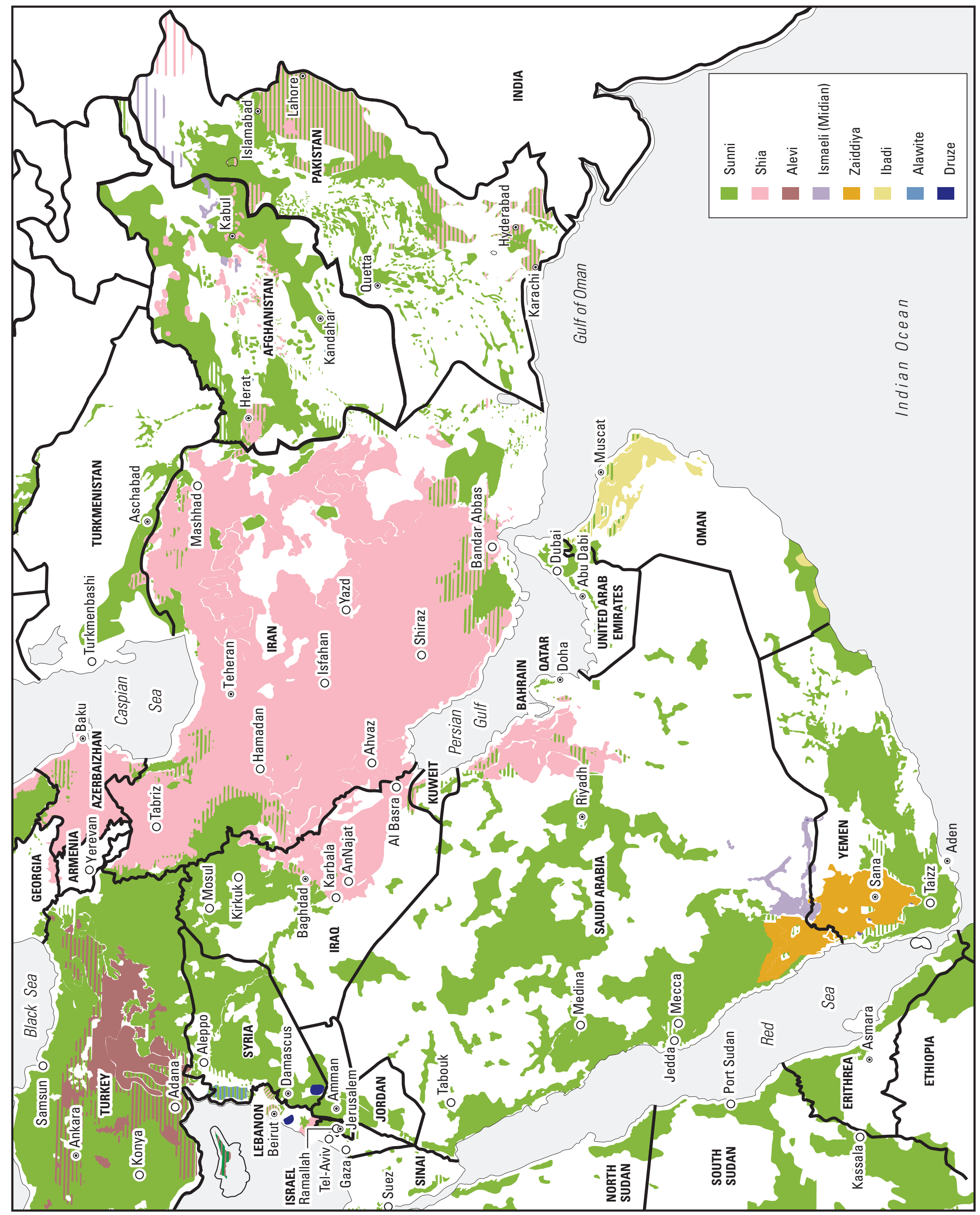



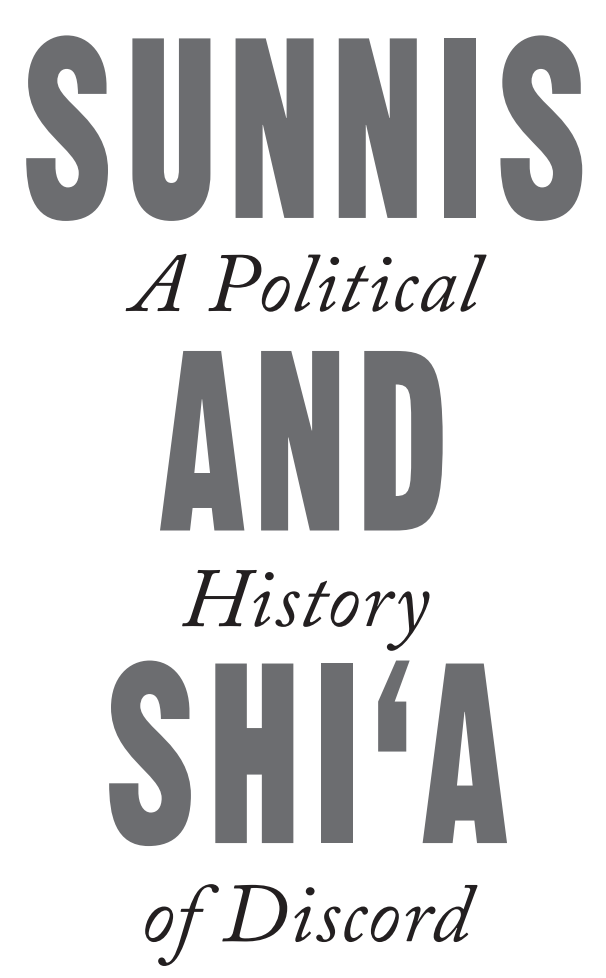

\section{Laurence Louër}

Translated by Ethan Rundell 
First published as Sunnites et Chiites: Histoire politique d'une discorde originally published Éditions du Seuil and is copyright (C) 2017 by Éditions du Seuil. The English translation by Ethan Rundell is copyright (C) 2020 by Princeton University Press.

Published by Princeton University Press 41 William Street, Princeton, New Jersey o8540 6 Oxford Street, Woodstock, Oxfordshire OX 201 TR press.princeton.edu

All Rights Reserved

Library of Congress Cataloging-in-Publication Data

Names: Louër, Laurence, author. | Rundell, Ethan S., translator.

Title: Sunnis and Shi'a : a political history of discord / Laurence Louër; translated by Ethan Rundell.

Other titles: Sunnites et Chiites. English

Identifiers: LCCN 2019027366 (print) | LCCN 201902 (ebook) | ISBN 9780691186610 (hardcover) | ISBN 9780691199641 (epub)

Subjects: LCSH: Shī'ah-Relations-Sunnites. | Sunnites-Relations-Shī‘ah. | Islam-Doctrines. | Islam and politics.

Classification: LCC BP194.16 .L6813 2020 (print) | LCC BP194.16 (ebook) | DDC 297.8/042-dc23

LC record available at https://lccn.loc.gov/2019027366

LC ebook record available at https://lccn.loc.gov/2019027367

British Library Cataloging-in-Publication Data is available

Editorial: Fred Appel and Jenny Tan

Production Editorial: Debbie Tegarden

Text Design: Leslie Flis

Jacket/Cover Design: Layla Mac Rory

Production: Erin Suydam

Publicity: James Schneider and Kathryn Stevens

Copyeditor: Anita O’Brien

This book has been composed in Arno Pro

Printed on acid-free paper. $\infty$

Printed in the United States of America

109887665543221 